\title{
Interaction of ergativity and information structure in Jaminjung (Australia)
}

DOI:

10.1093/oxfordhb/9780198739371.013.44

\section{Document Version}

Accepted author manuscript

Link to publication record in Manchester Research Explorer

\section{Citation for published version (APA):}

Schultze-Berndt, E. (2017). Interaction of ergativity and information structure in Jaminjung (Australia). In J. Coon, D. Massam, \& L. D. Travis (Eds.), Oxford Handbook of Ergativity (pp. 1089-1113). Oxford University Press. https://doi.org/10.1093/oxfordhb/9780198739371.013.44

\section{Published in:}

Oxford Handbook of Ergativity

\section{Citing this paper}

Please note that where the full-text provided on Manchester Research Explorer is the Author Accepted Manuscript or Proof version this may differ from the final Published version. If citing, it is advised that you check and use the publisher's definitive version.

\section{General rights}

Copyright and moral rights for the publications made accessible in the Research Explorer are retained by the authors and/or other copyright owners and it is a condition of accessing publications that users recognise and abide by the legal requirements associated with these rights.

\section{Takedown policy}

If you believe that this document breaches copyright please refer to the University of Manchester's Takedown Procedures [http://man.ac.uk/04Y6Bo] or contact uml.scholarlycommunications@manchester.ac.uk providing relevant details, so we can investigate your claim.

\section{OPEN ACCESS}




\section{CHAPTER 44}

\section{N T E R A C T I O N OF}

ERGATIVITY A N D

IN F ORMATION STRUCTURE

IN JAMINJUNG (AUSTRALIA)

\subsection{INTRODUCTION}

THIs chapter discusses the manifestations of ergativity in Jaminjung, a language of the small Mirndi family, spoken in northern Australia. Ergativity in Jaminjung is of interest in several respects. First, at the morphological level, Jaminjung is what has been described as an optional ergative language, since in many lexical and grammatical environments, the Ergative ${ }^{1}$ marker may or may not be present on agent NPs. This state of affairs thus differs from a split ergative system where the distribution of case marking is predictable and consistent on the basis of one or more grammatical factors such as the position of the agent referent on the animacy hierarchy, or the temporal or aspectual properties of the clause. It will be argued that the Jaminjung pattern can be described as a system of differential agent marking which is sensitive to multiple factors without strict constraints. One important factor is information structure, in that the presence of ergative marking strongly correlates with (but is not restricted to) focal status of the agent referent. However, factors that have been shown to trigger splits in split ergative systems - person, animacy, verb class, and tense/aspect-also play a role.

Second, as an alternative to the Ergative case, the Ablative case (i.e. the case form that is also used to flag the source location in motion expressions) is also found to mark agents, albeit much less frequently. When attempting to unravel the factors behind differential agent marking, one therefore needs to consider not only two but three possibilities: Ergative marking (default), Ablative marking, and zero marking. It will be argued in section 44.4 that information structure an important factor responsible for

1 I will use capital letters to refer to a language-specific case, and lower case to refer to the crosslinguistic category. 
Ergative or Ablative marking of agents. Third, Jaminjung exhibits a-cross-linguistically recurrent-identity of ergative and instrumental case.

Considered together, these three phenomena raise questions about the nature of case assignment and grammatical relations, since the use of the two agent cases is determined neither purely lexically nor purely structurally. It will be argued that a constructionbased framework combined with the notion of violable constraints is well suited for the analysis of ergativity in Jaminjung. In other words, speakers have at their disposal a range of argument structure constructions (for our purposes, ergative-marked NP, ablativemarked NP, and zero-marked NP). Since ergative marking in Jaminjung is restricted to bivalent predicates (in a sense to be refined in sections 44.2.1 and 44.2.3), the predicate licenses agent marking, but is not, on its own, sufficient for assigning case. Rather, the choice of construction in a particular context is also constrained by tense and aspect of the clause, person and animacy of the agent referent, and its discourse status.

In this chapter, the language name Jaminjung is used as a shorthand for a dialect cluster comprising of two named varieties, Jaminjung and Ngaliwurru (ISO-639: DJD). These are the only remaining members of the Jaminjungan (also Yirram or Western Mirndi) group of the Mirndi family, a discontinuous language family discussed by Chadwick $(1984,1997)$ and Harvey $(2008)$. The traditional country of the Jaminjung and Ngaliwurru people is situated immediately north and south of the Victoria River in the Northern Territory, between the present-day settlements of Victoria River Crossing and Timber Creek. Today speakers of both varieties-alongside members of other language groups-live in the traditional Ngaliwurru and Nungali country around Timber Creek as well as in Wadeye to the north and in the larger settlements of Katherine to the east and Kununurra to the west. Because of the scattered nature of the present-day population, it is difficult to accurately estimate the number of speakers, but it is probably fewer than 100. A large-scale language shift is underway to Kriol (also called Northern Territory Kriol and Roper River Kriol; ISO-639: ROP), an English-lexified Creole language that emerged as a result of the colonial situation and now functions as a lingua franca between Aboriginal people throughout a large area of northern-central Australia (Sandefur 1984; Harris 1986; Schultze-Berndt et al. 2013; Meakins 2014a).

Jaminjung and Ngaliwurru have been described in two unpublished grammars (Cleverly 1968; Bolt et al. 1971), in a number of papers by Hoddinott and Kofod (1976c, 1976a, 1976b), three unpublished PhD theses (Schultze-Berndt 2000; Simard 2010; Hoffmann 2011) and a number of published papers and conference presentations by the same authors (including Schultze-Berndt 2001, 2006a, 2007, 2010; Schultze-Berndt and Simard 2012; Simard 2013b, 2013a; 2015). The discussion in this chapter is based on annotated corpora compiled by the author between 1993 and 2012. Corpus examples are followed by speaker's initials and a unique reference number which identifies them in the archived corpus (DoBeS Endangered Languages Archive; http://dobes.mpi.nl/ research); this will be made accessible on request. Glosses follow the Leipzig Glossing conventions. Underline marks Kriol words.

The paper is structured as follows: section 44.2 provides a brief overview of the main relevant grammatical characteristics of Jaminjung, and adduces arguments for an analysis of 
the Ergative case as corresponding to the semantic role "effector", covering agents, natural forces, and instruments. Section 44.3 addresses the question of whether or not Jaminjung displays syntactic ergativity (the answer will be negative). The factors responsible for differential agent marking will be discussed in section 44.4. Section 44.5 is a summary with a brief discussion of the wider implications of the language-specific findings.

\subsection{ERgativity AND Argument Structure}

In terms of the morphosyntactic encoding of arguments and adjuncts Jaminjung is, in many ways, rather typical for languages of the Australian linguistic area (for an overview, see Gaby 2008b), and in particular the northern languages which do not belong to the large Pama-Nyungan language family. Core arguments are indexed on the verb, and argument roles are also indicated by a rich case system which in addition to the ergative/instrumental includes dative, purposive, motivational, origin (encoding place of origin, source, or cause), and comitative case markers, the spatial cases locative, allative, and ablative. Unlike many Pama-Nyungan split-ergative languages of Australia, Jaminjung has no differential object marking, i.e. there is no overt object marking (accusative case) for nominals of any category, or in any clause type. Transitive objects and intransitive subjects are always unmarked (a term used here interchangeably with Absolutive case).

The form of the Ergative case marker is $=n i$, often denasalized to $=$ di following a stop. The Ergative marker has been reported to be formally identical to the locative case (Hoddinott and Kofod 1976b); however, in my data, the Locative case marker, in the Ngaliwurru variety only, is $=n i$ postvocalically, but $=g i$ elsewhere (in Jaminjung it is $=g i \sim=g i$ ). The diachronic of the Ergative marker is very likely a third person pronoun or demonstrative, a point that will be further discussed in section 44.5 .

Case marking in Jaminjung is phrasal in nature, as already pointed out by Hoddinott and Kofod (1976b: 398). This is illustrated in (1) to (3) for the Ergative, but holds for the other case markers as well. Case markers can follow each word in a complex noun phrase, or only one of the words (they are not restricted to the edge of the phrase). The case markers are therefore analysed as clitics for the purposes of this chapter. The factors conditioning the variation in case position are not well understood at present and will not be further discussed here.

(1) $\quad$ ngiya=biya buluwuj=di $]_{T O P}$ digirrij ganiny-nginama! ${ }^{2}$

PROX=SEQ egg=ERG die 3 SG>3SG-step/weigh.PRS

these (bags of) eggs are killing you (by weighing down on you when you attempt to carry them)!

(IP; ESo8_Ao4_06.145)

2 See section 44.4 .3 for a definition of the information structure categories employed in the analysis. 

(2) “.." gani-yu=nu ${ }_{3} \mathrm{SG}>3$ SG-say/do.PST $=3$ SG.OBL “ “..." THIS man said to him'

(3) $[\text { janyju.. mangarra.. gagawurli }]_{\mathrm{TO}}$ DEM plant.food long.yam [ngarrgina $=n i \quad$ jungurniny $=n i]_{\mathrm{FOC}}$ 1SG.POSS=ERG husband=ERG

'that long yam food, it was dug it up by my husband' (ERa; ES12_Ao2_01.002-03)

\author{
$[\text { yinju }=n i \quad \text { gurang }]_{\mathrm{FOC}}$ \\ PROX=ERG older.man \\ (ERa; ESo8_A2O_03.119)
}

gan-ijja-ny..

${ }_{3} S G>3$ SG-poke-PST

While the phrasal nature of case marking is evidence for an (at least partially) configurational structure, Jaminjung is a "free word order" language in the sense that constituent order within NPs and complex predicates is variable to some extent and clause-level constituent order is more closely tied to information structure than to grammatical relations (see section 44.4.3; Simard 2010; Schultze-Berndt and Simard 2012). A frequent strategy is the distribution of information semantically belonging to a single clause across several intonation units (Simard 2013a).

Discourse-given participants need not be represented by overt NPs; a clause minimally consists of a (simple or complex) verb. As a consequence, the frequency of overt NPs, including agents, is relatively low. A text count conducted on a small corpus of texts revealed that only approximately $25 \%$ of all transitive predicates were accompanied by an overt agent NP (Schultze-Berndt 2006b). This will have to be kept in mind when considering the function and significance of case marking on agents.

The remainder of this section provides relevant information on the morphological and syntactic correlates of verbal valency (44.2.1), the interrelation of aspect and argument structure (44.2.2), and the range of functions of the Ergative marker (44.2.3), resulting in a definition of agents employed in the following discussion.

\subsubsection{Morphological and Syntactic Correlates of Argument Structure}

Before embarking on the discussion of argument structure and argument marking in Jaminjung, it will be necessary to clarify the application of the notion of "verb" for this language. One of the distinguishing properties of Jaminjung is the existence of two parts of speech which are restricted to predicative function. Inflecting Verbs (IVs) are a class of stems taking obligatory prefixes for person/number and a number of modal categories as well as tense/aspect suffixes (tense and aspect can also be marked by complete or partial stem suppletion). IVs form a closed class with only about 30 members (with some dialectal and individual variation). Only IVs can serve as the main predicate of finite, independent clauses. 
The second class is an open class of stems which cannot take any of the verbal inflections and for this reason is labelled Uninflecting Verbs (UVs), following McGregor (2002). UVs can function as the main predicate in some types of subordinate clause (see section 44.3). Their most frequent use is in complex predicates in combination with Inflecting Verbs. Jaminjung complex verbs meet the widely accepted definition of complex predicates as monoclausal constructions where two or more predicative constituents jointly contribute to the argument structure of the clause, share at least one argument, and share values for tense, aspect, modality, and polarity (see e.g. Butt 1997: 108; 2010). In terms of both their lexical semantics and their argument structure they form nuclear junctures in the sense of Role and Reference Grammar (Foley and Van Valin 1984; Van Valin and LaPolla 1997), or "merger" constructions in the terminology of Baker and Harvey (2010). In other words, the complex predicate behaves like a single verb in that it takes a single set of arguments, and neither of the components can introduce an additional participant that would duplicate a grammatical function already contributed by the other, as would be the case e.g. for a serial verb construction involving two bivalent predicates each taking different objects. Two complex predicates involving the same UV but differing in their overall argument structure are illustrated in (4).
(4) a. bag ga-jga-ny=ni bottle
break $3 S G$-go-PST=DS bottle
'the jar broke'

b. bag-bag gana-nangga=biyang

RDP-break 3 SG $>3$ SG-chop.IPFV=SEQ mother's.brother=ERG

'my uncle used to break them (quartz stones) up' (EH, ESo8_Ao4_02.234)

By virtue of being semantically generic, the closed-class IVs take on the nature of overt event classifiers. For example, the intransitive IV -ijga 'go' in (4) regularly occurs in expressions of motion, but also in expressions of change of state, and thus specifies the general type of event that the complex predicate encodes. The argument structure and semantic composition of Jaminjung complex predicates is discussed in more detail elsewhere (Schultze-Berndt 2000, 2007, 2010, 2012, 2015).

Morphologically, inflecting verbs (IVs) fall into two non-overlapping classes. Intransitive IVs only inflect for the person/number of a single argument $(\mathrm{S})$, while transitive IVs index two arguments; these are the Actor (A) and Undergoer (P) for monotransitive predicates and (usually) the Actor and Recipient for ditransitive predicates. Reflexive-reciprocal forms can be formed from most morphologically transitive IVs; the resulting forms are morphologically and syntactically intransitive, i.e. they only index a single participant (with the intransitive person paradigm).

As a default, the $S$ argument of intransitive verbs (including reflexive/reciprocal verbs) is encoded by a zero-marked (absolutive) NP (if present), as is the $\mathrm{P}$ argument of transitive verbs, and both the Recipient and Theme arguments of ditransitive 
verbs (Schultze-Berndt 2010). The A argument of transitive and ditransitive verbs, on the other hand, has the three case-marking possibilities mentioned above (zero, ergative, or ablative). There is no class of transitive verbs that is singled out for "special" subject marking (as found e.g. for experiencers in many languages). Intransitive subjects are never ergative-marked, unlike in a number of other "optional ergative" languages.

One consequence, relevant in the context of ergativity, of the complex predicate structure just discussed is that Jaminjung has no ambitransitive predicates corresponding e.g. to English to break or to open. IVs as simple predicates are either strictly monovalent, bivalent, or trivalent. In complex predicates, transitivity alternations with the same UV always involve a change of IV, as illustrated in (4) (SchultzeBerndt 2015). This means that the presence of ergative case marking is unlikely to be related to the need to distinguish a transitive from an intransitive reading of the same predicate.

While, as a general rule, the number of core arguments and the case frame used with a particular (simple or complex) predicate corresponds to the morphological transitivity of the IV, there are a number of deviations from this general rule. These involve specific secondary meanings of IVs in complex predicates, which are at odds with their morphological class. For example, the morphologically transitive IV - ma 'hit' can be used to form complex verbs of emerging and appearance which are syntactically intransitive, allowing only a single, absolutive NP, as illustrated in (5). Two other cases of mismatch between morphological and syntactic argument structure will be discussed in sections 2.2 and 2.5; for details see Schultze-Berndt (2015).
(5) jarlig
majani bul
gani-ma-m=nu
child(ABS) maybe emerge
3SG $>3$ SG-hit.PRS=3SG.OBL
'maybe the child appears on her'
(JM;ES12_Ao4_01.193)

Apart from the derivational reflexive/reciprocal formation and the possibility of combining the same UV with different IVs, Jaminjung has no valency changing devices. Neither does it have voice such as a passive or antipassive constructions (though see the remarks on the 'pseudo-progressive construction' in section 44.2.2).

\subsubsection{Aspect and Argument Structure}

As indicated above, tense and aspect are marked on the Inflecting Verb (IV) in Jaminjung. The categories that are distinguished-variably marked by suffixes or stem suppletion-are Present Tense (PRS; unspecified for aspect), Past Perfective (PST) and Past Imperfective (IPFV). Modal categories are marked by prefixation; in addition to Imperative mood, Jaminjung has an untensed modal category ( mainly used in contexts of negative and undesirable possibility, and a possibility (Potential) 
modal (POT) which in untensed clauses has future and desiderative functions and which is also compatible with the Past Imperfective in a past possibility reading. The correlation between inflectional tense/aspect and the presence or absence of ergative marking will be considered in section 44.4.2.

In addition to the inflectional imperfective, there is an imperfective construction (termed 'Pseudo-Progressive' by Schultze-Berndt 2012) which involves iterative marking on an Uninflecting Verb and the choice of one of the two morphologically intransitive Inflecting Verbs - $y u$ 'be' or -ijga 'go'. This construction has some relevance for the discussion of ergativity since it is incompatible with ergative marking even in the case of bivalent predicates. If overt, both core participants are in the (unmarked) absolutive case, as shown in (6).

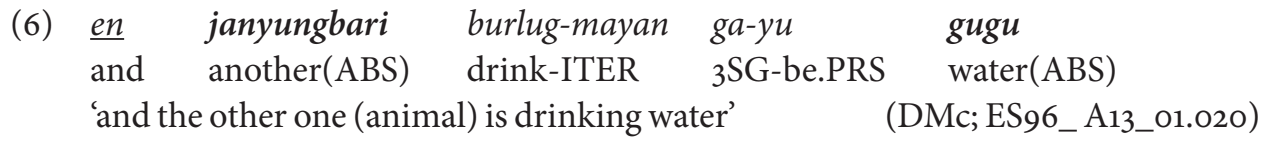

A double absolutive frame in progressive or otherwise imperfective constructions is a cross-linguistically recurrent phenomenon; it has been described, for example, by Laka (2006a) for Basque and Forker (2012) for Nakh-Daghestanian languages. The absence of agent marking in this case is conditioned by the use of an intransitive predicate (originally with locative semantics), as is cross-linguistically common in the encoding of a progressive structure (e.g. Bybee et al. 1994: 129-137; Laka 2006a; Coon 2013a). If one considers mainly the intransitive properties of the construction, it has affinities with antipassive constructions, which are often imperfective in nature (Cooreman 1994: 57-58; Polinsky 2013). The pseudo-progressive overlaps with a canonical antipassive in featuring an absolutive Agent, while failing to meet the criterion of an oblique or obligatorily demoted object. If one considers mainly the transitive nature of the construction-i.e. the fact that it allows for an absolutive object in the case of bivalent predicates-it represents a clear ergative split based on aspectual properties, as opposed to the more fluid factors influencing the presence or absence of ergative marking to be discussed in section 44.4 .

\subsubsection{Actors, Agents, and Instruments: The Notion of Effector}

The Jaminjung case form which is the default agent marker and is therefore labelled Ergative case here is found with arguments in a range of semantic roles. It can mark volitional human agents as in (3), non-volitional animate actors as in (7), inanimate forces as in (8), and other inanimate causes of an event as in (1). There is no evidence that differential agent marking in Jaminjung is conditioned by conscious choice or volitionality of the agent, as can be the case e.g. in Hindi/Urdu (Mohanan 1994a: 72ff.; Butt 1997: 122; De Hoop and Narasimhan 2005, 2009). 
(7) jarlig=biya bardawurru gani-ma-ya $\backslash$. . child $=$ SEQ many 3 SG $>3$ SG-have-PRS 'it has many children, the emu (does)' [gumurrinyji=ni=malang $]_{\mathrm{FOC}}$ emu=ERG=GIVEN

(DM, MH96_A19_01.049-50)

(8) $[\text { wilarung=ni ganurr-ina- } m]_{F O C}$ "da:::"

lightning=ERG $\quad{ }_{3} \mathrm{SG}>3$ PL-chop-PRS (sound)

'the lightning strikes them, "daaaa"'

(IP, ESo8_A16_02.012)

In all the examples so far, the ergative-marked NP is coreferential with a pronominal index on the inflecting verb in the first, A(ctor) slot (see section 44.2.1). The Ergative case is however also used to mark instruments as in (9) and (11), a functional overlap common in Australian languages, but also cross-linguistically. As expected, the verb in this cases indexes person and number of the agent, not the instrument, and the agent can be represented by a second ergative-marked noun phrase as shown in (9).
(9) thanthu=ni=biyang warn gani-bili wirlga=ni
$\mathrm{DEM}=\mathrm{ERG}=\mathrm{SEQ}$ entangle $3 \mathrm{SG}: 3 \mathrm{SG}-\mathrm{POT}$ :get/handle foot=ERG/INST
'that one (the owl) is going to grab him (the boy) with its claws' (IP, ES97_Ao3_01.170)

In most traditional accounts, ergative and instrumental are analysed as homophonous markers of two distinct grammatical roles (e.g. Blake 2001 [1994]: 49-50). Laughren (1992) accounts for ergative marking on instruments in Warlpiri by analysing instrumental NPs as secondary predicates controlled by the agent, since ergative marking of instruments is restricted to transitive predicates. However, the distinction between "instruments" and "agents" is not clear-cut. While Ergative-marking of instruments is likewise restricted to transitive predicates in Jaminjung, the Ergative case is also found with the inanimate agent co-occurring with a morphologically intransitive verb, -irna 'burn, be affected by heat', illustrated in (10).
(10) jarlig wuju ga-rna guyug=di child small 3 SG-burn.PST fire $=$ ERG 'the little child got burnt by the fire'

(JM, fieldnotes 1993)

I argue here that the Jaminjung Ergative case has a single overall function, that of marking the role of "effector" (Van Valin and Wilkins 1996; Bickel 2000: 599f.) or "initiator" (Legate 2012a: 183). This is taken to be a language-specific semantic role (in the sense of a semantic role directly reflected in morphosyntax) involving a participant that is causally involved in an event which impinges on an undergoer (hence the restriction of ergative marking to two-participant scenarios, as opposed to simply "agentive" scenarios). The basic assumption underlying this analysis is that arguments 
form constructions in their own right and consequently express constructional meanings which have to be compatible with, but are not determined either by the meaning of the predicate ("lexical case"), or by the overall structure of the clause ("structural case") (Goldberg 1995; Barðdal 2011). This assumption is in turn based on the observation that the functions of case markers are not equivalent cross-linguistically even if they share some core uses (e.g. the occurrence on typical agents of typical transitive clauses).

The analysis of the Jaminjung Ergative case as encoding the role of effector subsumes all functions discussed above, including that of the heat source with a 'burn' predicate, the sentient participant with experiencer predicates, and the controlling participant with transitive predicates of possession. The Effector role differs from the role of the Actor participant which is indexed by the first (A) prefix of transitive predicates, which is much more restrictive in that it is only compatible with participants which are the ultimate cause (first cause) of an event (DeLancey 1991; Van Valin and LaPolla 1997: 146). This analysis is supported by the fact that the ergative-marked heat source with intransitive IV -irna 'burn' is always inanimate (fire, ashes, or the sun). With animate agents (or the sun) - ultimate causes of a fire-the transitive 'burn' verb -irriga 'cook, burn' is required, as in (11).

$$
\begin{aligned}
& \text { (yurlgi) guyug=di burru-rriga }=n u, \quad \text { jag=gu } \\
& \text { leech fire }=\mathrm{ERG} / \mathrm{INST} \quad{ }_{3} \mathrm{PL}>{ }_{3} \mathrm{SG}-\mathrm{cook} . \mathrm{PST}=3 \mathrm{SG} . \mathrm{OBL} \text { go.down=DAT } \\
& \text { 'they burnt (the leech) with fire for her, so that it would fall off' }
\end{aligned}
$$

(IP, ES97_A03_02.179)

In sum, the morphological Ergative case in Jaminjung is the marker of an agent role in a broad sense ("effector", "instigator"), subsuming instruments and natural forces. The discussion of ergativity in the following sections will be restricted to agents in the narrow sense (i.e. the agentive arguments of transitive predicates), excluding instruments. Agents in Jaminjung will be defined as arguments that (i) are indexed by a person/number prefix on the verb and (ii) are potentially ergative-marked. This definition excludes the single argument in cases like (5), which meets criterion (i) but not (ii). Criterion (ii) also excludes the-obligatorily absolutive-first argument of bivalent predicates formed with intransitive inflecting verbs in the "pseudo-progressive" imperfective construction (44.2.2). Instruments are excluded by criterion (i) since they are not indexed on the verb. However, the definition includes Ergative-marked phrases encoding a heat source with the morphologically intransitive verb -irna 'burn', as in (10). On agents thus defined, the Ergative is the default case in terms of its frequency, but is not obligatory; moreover, the Ablative case can also mark the agent role, but does not fully overlap in meaning with the Ergative in that it is restricted to animate agents (see section 44.4.4). 


\subsection{The Issue of Syntactic Ergativity}

A question not addressed so far is whether Jaminjung exhibits not only a morphological ergative-absolutive case marking pattern, but also syntactic ergativity, i.e. whether any syntactic pattern singles out either the ergative (A) or the absolutive (S/P) function.

Standard diagnostics for syntactic ergativity are argument omission in clausal coordination, relativization, control relations between main and subordinate clause, and switch-reference constructions. The coordination test does not work for Jaminjung because, as discussed in section 44.2, all discourse-given arguments can be omitted. Relativization is not a good diagnostic either because Jaminjung only has a generalized subordinate clause corresponding to Hale's (1976a) adjoined relative clause which, in addition to reference-identifying ("relative clause") functions, also has temporal and circumstantial uses and thus do not require a head (see also Nordlinger 2006).

Only control turns out to be an unambiguous diagnostic for Jaminjung, and to reveal nominative-accusative patterning. This is because direct objects (in absolutive case, and indexed by the Object prefix of transitive verbs) and some types of Dative-marked objects control the unexpressed subject of a type of simultaneous non-finite clause marked with the clitic =bina $\sim=$ mina, formally identical to the Allative case. Examples (12) and (13) provide illustration. A parallel construction is found in other languages in the same linguistic area, e.g. Warlpiri (Simpson and Bresnan 1983; Legate 2012a: 184) and Wardaman (Merlan 1994: 287).

(12) $\quad$ gurrija=bina $]_{C L-N F I N}$ waj yirrurr-unga-ny $\backslash$ digging=ALL leave.behind 1 PL.EXCL $>3$ PL-move.away.from-PST 'we had left them ${ }_{\mathrm{i}}$ (while they $\mathrm{i}_{\mathrm{i}}$ were) digging'

(DP, ES96_Ao9_03.156)

(13) "gujarding=ni ngarrgina=ni gan-anjama-ny mother $=$ ERG $\quad 1$ SG.POSS $=$ ERG $\quad 3$ SG $>3$ SG-bring-PST

yinju=biya=nggu $\backslash \quad$ wajgany" $\backslash$ gan-unggu-m=nu $\backslash$

$\mathrm{PROX}=\mathrm{SEQ}=2 \mathrm{SG} . \mathrm{OBL}$ honey $3 \mathrm{SG}>3 \mathrm{SG}-$ say $/$ do $-\mathrm{PRS}=3 \mathrm{SG} . \mathrm{OBL}$ mugurn=bina $\backslash$ lie/sleep $=$ ALL “"my mother brought this sugarbag for you" she said to her $\mathrm{r}_{\mathrm{i}}$ ( while she $_{\mathrm{i}}$ was) lying down'

(VP; ES99_Vo1_06a.105-7)

In contrast, simultaneous non-finite clauses where the unexpressed subject corresponds to either the S (14) or the A argument (15) of the matrix clause can take the iterative marker = mayan if the subject is understood to be agentive.

(14) CaveSpring=bina yurr-ijga-ny=mulu $\backslash \quad$ [bilij garrb=mayan $\backslash$ $<$ place.name $>=$ ALL 1 PL.INCL-go-PST $=$ COLL ashes gather=ITER 'all of us went to Cave Spring, gathering ashes' (IP, ESo8_Ao4_01.007-8) 


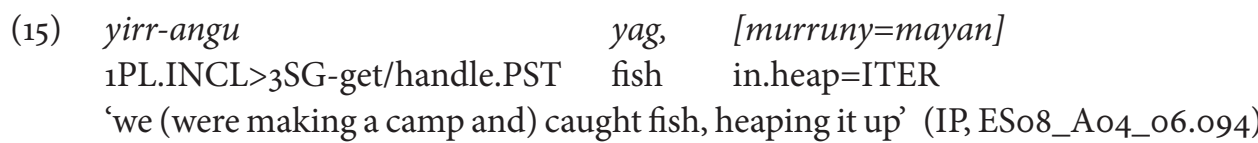

Control phenomena thus single out the object of transitive clauses as opposed to the subject of transitive or intransitive clauses-a nominative/accusative pattern. A nominative/accusative pattern is also displayed by an additional switch-reference construction which applies to a sequence of finite clauses. This is marked by an enclitic on the inflecting verb, which signals non-identity between the S or A of the clause hosting the clitic and that of a preceding clause, as illustrated in (16) to (18).

(16) buwu ga-rdba-ny gugu=bina, guyug=biya

dive 3 SG-fall-PST water $=$ ALL

fire $=$ SEQ

ngarnarnabma ga-rna=ni gurunyung=gi

glowing 3 SG-burn.PST=DS head=LOC

(of a mythical man who had tied up a firestick in his hair when crossing a river) 'he dived into the water, (but) the fire kept burning on his head'

(IP, ESo1_A03_07.006-7)

(17) ngab gan-ma, naru nga-rdba-ny=ni

miss 3 SG $>$ 1SG-hit.PST dodge 1 SG-fall-PST $=$ DS

'he missed me (when trying to throw something at me), (because) I dodged' (EH, ESo3_Ao2_01.375)

(18) ERa: Jub Jgani-bili, $\_$ngali?
come.off 3 SG $>3$ SG-POT:get/handleTTAG

JM: dugulg gani-minda-ny=ni swallow $3 \mathrm{SG}>3$ SG-eat-PST $=\mathrm{DS}$

(watching a video of a woman trying to pull a hook out of a fish she has caught): ERa: 'she wants to pull it (the hook) out, right?'-JM: 'it (the fish) swallowed it'

It should be noted that the different subject marker is not obligatory in such contexts, and moreover appears to have a wider application of indicating lack of topic continuity, rather than necessarily flagging different subject status in the grammatical sense. An example is (19), from a description of a number of photos showing the speaker's family engaged in building a shade. The two sentences-which are separated by a distinct pause-have in fact the same subject but represent descriptions of two different scenes.

(19) gujarding-guluwa gurdij ga-yu Lidipimen mother-KIN2 stand 3 SG-be.PRS CDEP:man '(here look), your mother is standing up, the CDEP person' (... 3 sec pause, new photo selected) 
ngiya=biya gujarding-guluwa tharda ga-yu=ni bayi-bayirr $\mathrm{PROX}=\mathrm{SEQ}$ mother-KIN2 face.away 3 SG-be.PRS=DS RDP-supported 'here is your mother facing away, being all over the top (of the roof)'

(IP; ES97_Ao3_10.032-33)

Intriguingly, the different subject marker actually shares a form with the ergative marker, and both plausibly originate in a third person singular pronoun or deictic, an observation that we will return to in section 44.5.

In sum, there is no evidence for an absolutive (or ergative) pivot in any complex construction, and therefore Jaminjung cannot be considered a syntactically ergative language. In fact, two complex constructions-a control construction involving allativemarked non-finite subordinate clause, and a switch-reference construction applying to a sequence of finite clauses-display nominative/accusative alignment.

\subsection{FACTORS INFLUENCING Morphological ERgativity}

The phenomenon known as "fluid A marking" or "optional ergative marking" has received considerable attention in the recent linguistic literature, as has the wider research area of which it forms a part, differential argument marking (see section 44.4.1 for further discussion and references).

As already indicated in section 44.1, Jaminjung has a three-way differential agent marking system, with the options of ergative marking (the most frequent option, found on $72 \%$ of the agents in a preliminary dataset), ablative marking (the least frequent option, found on less than $7 \%$ of agents), and zero marking (22\%). This section provides an overview of the-multiple-factors triggering the presence or absence of case marking on Agents in Jaminjung. It will be argued that differential agent marking in Jaminjung is sensitive to information structure, in addition to various factors that have recognized as triggering split agent marking: verb semantics, tense and aspect, person, and animacy.

The discussion of optional ergativity in Jaminjung presented here is based on a preliminary discourse study of a total number of 32 texts (amounting to approximately 6,600 intonation units) representing a range of discourse genres including mythological and personal narratives, procedural texts, retellings of picture books, other descriptions of visual stimuli, and conversations. These were manually scanned for overt Agent expressions (as defined in section 44.2.3), and the relevant examples coded for information structure category of the agent phrase (argument focus, broad focus, and topic), person, animacy in the narrow sense, their formal expression (pronoun, pronominal demonstrative, noun phrase with lexical head, and, for objects, also quotation and zero), constituent 
order, tense/aspect/modality (using the inflectional categories of the verb as described in section 44.2.2), semantic class of verb, and speaker. The number of clauses with Agent phrases in this set of texts is relatively low (282, amounting to approximately one agent noun phrase in 20 intonation units) which is not unexpected given cross-linguistic observations about the frequency of overt agent noun phrases in any language allowing for argument omission. An expanded study, based on a larger dataset and detailed discussion of the factors identified for Agent marking, is presented in Schultze-Berndt and Meakins (in prep.). The following discussion reports on the most robust findings. In order to contextualize the discussion, I will briefly review the literature on optional ergativity and the factors identified in studies of other languages (section 44.4.1). Section 44.4.2 deals with the semantic factors which can been identified as responsible for the presence vs. absence of agent marking (subsuming the Ergative and Ablative variants). Section 44.4.3 provides a brief definition of the information structure categories employed and discusses their influence on overt agent marking. Section 44.4.4 examines in more detail the conditions under which the (infrequent) Ablative marking of agents is found.

\subsubsection{Variable Ergative Marking Cross-Linguistically}

Fluid A marking ("optional" ergative marking) is attested in many ergative languages of Australia, New Guinea, and the Himalayan region, but also outside these regions, e.g. in languages of the Chibchan family (Quesada 1999) and in the Kawapanan language Shiwilu, spoken in the Peruvian Amazon (Valenzuela 2011). Factors that have been described as influencing the presence vs. absence of ergative case in these languages include those that had long been identified as underlying clear-cut split systems. One of these is verb semantics and/or degree of affectedness of the object, in that some verb classes require or favour ergative marking, e.g. the verb 'know' in the Tamangic language Manang Gurung (Bond et al. 2013).

A second factor is tense and aspect. For example, obligatory ergativity in past perfective contexts, combined with optional ergative marking in non-past and imperfective contexts, has been reported for languages of the Himalayan region including Nepali (Li 2007) and spoken Lhasa Tibetan (Tournadre 1995; Denwood 1999: 195-198); again this distribution is in line with that described for tense/aspect-based split ergative systems.

A third factor is the position of the agent argument on the referential (empathy or "animacy") hierarchy (local pattern), or the relative position of agent and undergoer on the hierarchy (global pattern). Both are considered relevant for Kuuk Thayorre by Gaby (2008a). In many fluid A languages, ergative marking is in fact obligatory for inanimate As such as natural forces, e.g. Gooniyandi (McGregor 1992), Umpithamu (Verstraete 2010), Gurindji Kriol (Meakins 2011: 225), Nepali (Li 2007; Bickel 2011: 407), Fore (Scott 1986) and Qiang (LaPolla and Huang 2008: 80) (see also McGregor 2010: 1617). For referents other than inanimates, animacy in the narrow sense rarely appears to be relevant for differential A marking of any sort (Fauconnier and Verstraete 2014: 14-16). However, the distinction between speech act participants and third persons - a frequent factor in 
split ergative systems especially in the Australian context-also plays a role in the distribution of ergative marking in "fluid A" languages, e.g. Japhug Rgyalrong (Jacques 2010); this also applies to Jaminjung.

In addition, a growing number of studies point to the importance of factors related to discourse organization and speaker and hearer's common ground in accounting for variable ergative marking. This parallels a similar recognition of information structure as a factor responsible for differential object marking (Nikolaeva 1999, 2001; Iemmolo 2010; Dalrymple and Nikolaeva 2011). Due to its dependence on the discourse context, variable agent marking of this kind cannot result in a clear-cut split based on traditional grammatical or semantic factors in the same way as e.g. verb class and animacy; in other words, these factors will not be found in systems traditionally classified as "split". Recent overviews and further references can be found in McGregor (2010), Chelliah and Hyslop (2011), DeLancey (2011), Malchukov (2008a) and Fauconnier and Verstraete (2014).

The discourse-pragmatic function of ergative marking has been described in different terms by different authors. Notions that are often invoked to account for the presence of ergative marking are "focus/new information" (e.g. Tournadre 1991; Tournadre 1995; Denwood 1999: 197; Malchukov 2008a; Chelliah 2009; Hyslop 2010: 13-17; Suter 2010; Verstraete 2010; Fauconnier and Verstraete 2014), contrast (e.g. Tournadre 1991; Chelliah 2009; Jacques 2010), topic/actor switch (e.g. Lidz 2011; Bond et al. 2013), or expectedness of the agent (McGregor 1992, 1998; Gaby 2008a). Some authors employ a notion of prominence or (contrastive) emphasis, cross-cutting focus, and topic categories (Tournadre 1991, 1995; LaPolla and Huang 2008; Meakins 2009: 78; Meakins and O'Shannessy 2010; 2011: 228-236). The notion of "prominence", and a similar notion of "(argument) strength" is given an even wider interpretation-variably encompassing a high rank on the animacy hierarchy and discourse topicality as well as perfectivity of the clause and volitionality of the agent referent-in some recent works addressing differential argument marking from an optimality-theoretical perspective (Legendre et al. 1993: 684-688; Aissen 1999b; De Hoop and Malchukov 2007). As De Hoop and de Swart (2009: 14) point out, employing such a broad notion of prominence leads to the somewhat unsatisfactory conclusion that in some languages it is highly prominent agents that are case-marked and in others, agents low in prominence.

Languages exhibiting discourse-pragmatic uses of agent markers also vary in whether or not these are extended to the single arguments of intransitive verbs, thereby raising the question of the appropriateness of an "ergative" analysis of the relevant construction (Tournadre 1991: 100-102; Li 2007; Gaby 2008a; Meakins 2009; Gaby 2010; Hyslop 2010; Suter 2010; Meakins 2015). Of particular interest are atso reported cases of "ergative" markers with uses which extend even further from that of case marker of transitive agents, and which are therefore analysed as general markers of contrastiveness or focus. Examples are Meithei (Chelliah 2009) and Jingulu, a language remotely related to Jaminjung and featuring an ergative / focus marker which is cognate with the Jaminjung ergative marker (Pensalfini 1999). As indicated in the previous discussion (section 44.2.1), in Jaminjung ergative marking is restricted to transitive predicates. 
The fourth factor just discussed, discourse-pragmatic function and information structure, is shown to interact with some of the other factors in many studies of "optional" ergativity. To give just a few examples, in Kurtöp, some verb classes require ergative marking of agents but for others, ergative marking signals contrastive focus (Hyslop 2010). Jacques (2010: 131) claims that for Japhug Rgyalrong, 1st and 2nd person pronouns rarely receive ergative marking, but if they do it is in contrastive function. In Qiang, ergative marking is obligatory with inanimate agents, but is only present in an "emphatic" function with other categories on the animacy hierarchy (LaPolla and Huang 2008: 76-88). The conditions favouring the presence vs absence of case-marking on agents in Jaminjung are of a similar multifactorial nature, as will become clear in the next three subsections.

\subsubsection{Semantic Factors Responsible for Presence vs. Absence of Agent Marking}

The factors to be considered in this section are verb class, tense and aspect, and person and animacy of the agent referent. These are the semantic factors identified in 44.4 .1 as having parallels in systems with obligatory split ergativity. This will be followed in 44.4 .3 by an investigation of the role of information structure in favouring the presence or absence of ergative marking. For expository reasons, in this and the following section, Ergative and Ablative marking will be subsumed under the category of "(case-)marked". Ablative marking will be considered separately in section 44.4.4.

Considering only the semantics of the (simple or complex) predicate, the transitive verb of possession (-muwa $\sim-m a=$ 'have') and expressions of speech in conjunction with a quotation behave strikingly different from all other predicate classes in Jaminjung. Whereas the frequency of case-marking (as opposed to zero marking) lies between 80 and $90 \%$ for all other predicate classes, with transitive possession and direct speech expressions only just over $50 \%$ of agents are case-marked.

The most plausible explanation for this distribution is "effectiveness" in the sense of Tsunoda (1981b) and DeLancey (1981), i.e. degree of affectedness of the undergoer. This is low in the case of "uncontrolled" possession, i.e. inalienable (part-whole) relationships, as in (20) (incidentally one of the rare cases where inanimate As can be unmarked; see further below), or the case of animals having eggs or young, which accounts for many of the zero-marked examples in the dataset.

(20)

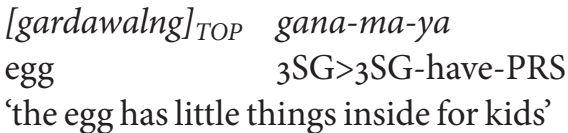

$$
\begin{array}{lll}
\text { wuju-wuju } & \text { mali jalig-gina } \\
\text { RDP-small } & \text { thing } & \text { child-POSS }
\end{array}
$$

(describing kinder surprise eggs)

In contrast, whenever - muwa $\sim-m a$ 'have' is used with an animate object in a sense of 'look after, keep', as in (21), it always occurs with a case-marked agent in the dataset. 
Note however that the contrast is not clear-cut-in the sense that one could assume two distinct senses of 'have' with two distinct case-frames-because even part-whole relationships can be expressed with case-marked agents/possessors, e.g. under conditions of focus (see 44.4.3).



(VP, ES99_Vo1_06a.095)

As already mentioned, a high ratio of unmarked agents in clauses involving the generic verb -ju(nggu) 'say/do', with reported speech filling the role of undergoer, as illustrated in (2). Formally, this verb has the main transitive properties-the ability to occur with ergative marking, and the use of the transitive person prefix paradigm. It is however a defective transitive verb in that it fails to form a reflexive/reciprocal (see section 44.2.1). Moreover, the quotation is not a typical object, and the clause containing the agent phrase may be more appropriately described as a "framing" construction than as a main clause with anbedded reported speech (McGregor 1994; Rumsey 2010). Prosodically, the speech framing constructions can have "parenthetical" status as reflected in an overall lower pitch, narrower pitch range, and lower intensity.

In addition to the overall effects of particular predicates, it is quite possible that the presence vs. absence of agent marking can indicate a difference in affectedness of the object even with the same predicate, as has been argued for Gooniyandi by McGregor $(1992,1998)$. This possibility is illustrated in (22) and (23), which feature the same inflecting verb of motion -unga 'leave', but encode events which differ in impact on the object left behind: a pet frog leaving its 'owner' in (22) and a mother leaving her child-even if temporarily, to go hunting-in (23). Note however that the two sentences also differ in information structure.
(22) [malara=biya $]_{T O P}$ dibard ganuny-ngunga-m, ba-ngawu frog=SEQ jump $3 \mathrm{SG}>3$ DU-leave-PRS IMP-see 'the frog now is leaving the two jumping away, look'

(Frog Story; IP, ES97_A03_01.047)
(23) majani [gujarding=ni waj gan-unga-m $]_{\mathrm{FOC}}$ maybe mother=ERG leave.behind $3 \mathrm{SG}>3 \mathrm{SG}$-leave-PRS 'maybe the mother leaves her (a child)' (VP, ES99_Vo1_o6a.078)

Such more fine-grained effects have been left out of consideration in the overall analysis. However, the saliently distinct behaviour of the two verbs -ju(nggu) 'say/do' and 
- muwa -ma 'have', compared with other transitive verbs, will be kept in mind when investigating the remaining factors responsible for ergative marking.

The next potential factor to be discussed is tense, aspect, and modality. Here we find a contrast between past perfective clauses and all other inflectional tense/aspect $/$ modal categories (see section 44.2.2): if one excludes clauses with quotations as objects-for the reasons discussed above-case-marking is nearly always present in (94\% in the preliminary study) but only present in around $75 \%$ of clauses for all other categories. (Note however that periphrastic imperfective constructions categorically have unmarked agents, as discussed in section 44.2.2.) This is of course precisely what is predicted on the basis of what is known about split ergative systems-if there is a split on the basis of tense or aspect, past and perfective categories will have ergative-marked agents, and nonpast and imperfective categories will have zero-marked agents. In the case of Jaminjung, the (relatively weak) tendency mirrors the split found in other languages. Modality, on the other hand-described as a factor in fluid ergativity for languages such as Meithei (Chelliah 2009: 389) - does not play a role in Jaminjung: modal clauses with future time reference are not any less likely to have ergative-marked Agents than non-modal clauses.

Finally, split ergativity is frequently associated with position on the so-called animacy (or empathy) hierarchy, although animacy in the narrow sense may not be the most important factor. Rather, splits are particularly likely to occur between 1st/2nd person and all other persons (DeLancey 1981: 645; Mallinson and Blake 1981: 86; Aissen 1999b: 679; Song 2001: 170), or pronouns vs. lexical NPs (DeLancey 1981: 645; Comrie 2013a). Moreover, as indicated in section 44.4.1, in many languages with optional ergativity, ergative marking has been described as obligatory for inanimate agents.

Jaminjung shows a very clear tendency for speech act participants (1st/2nd person pronouns) to appear as unmarked agents, mirroring the pattern in consistently split ergative languages: in the preliminary study, only $17 \%$ of speech act participant pronouns were marked with either of the two agent cases. For all other human referents, on the other hand, agent marking is the clear default, found in $81 \%$ of all cases. For non-human animates, the ratio increases to $87 \%$ of marked agents. Inanimates are almost invariably ergative marked, but this is not an exceptionless generalization, as illustrated by example (20).

Proper names or kinship terms, just like other human categories, allow for either presence or absence of case marking; ergative marking with a proper name is illustrated in (24).

$\begin{array}{llll}\text { (24) }[\wedge \text { Ben=ni=biyang }]_{\mathrm{FOC}} & d u & \text { gan-ijja-ny=burri } & \text { gurunyung } \\ \text { proper_name }=\mathrm{ERG}=\mathrm{SEQ} & \text { shoot } & 3 \mathrm{SG}>3 \mathrm{SG}-\text { poke-PST }=3 \mathrm{PL} & \text { head }\end{array}$ 'BEN then shot it (an echidna) in the head for them' (IP, ESo8_Ao4_06.468)

Thus, two clear trends emerge for the interaction of animacy with agent marking: near-obligatory marking on inanimates, and zero-marking as a default for $1^{\text {st }}$ and 
$2^{\text {nd }}$ person pronouns, both in line with cross-linguistic expectations. It is moreover instructive to consider the exceptions to the generalization: all six instances of casemarked personal pronouns are NPs in narrow (argument) focus. This leads us to the next factor, information structure.

\subsubsection{The Role of Information Structure in the Case-Marking of Agents}

The literature reviewed in section 44.4.1 points to a role of information structure-and possibly, additional factors of discourse organization-in determining the presence or absence of case marking on agents in Fluid Ergative systems. This section discusses evidence for some influence of information structure on agent marking in Jaminjung. In order to base the investigation on reasonably clearly defined notions, the information structure category of overt agent phrases was determined on the basis of contextual criteria-to be briefly introduced below-in combination with prosodic criteria and constituent order. This builds on the detailed, quantitative prosodic analysis by Simard (2010), which establishes the prosodic correlates of topic and focus phrases in Jaminjung.

In line with convergent views in recent research, the analysis assumes a definition of focus as the expression that fills a variable in an open proposition, the latter corresponding to the background part of the clause (which can be conceptualized as an implicit, or sometimes explicit, question under discussion). In other words, a focused item evokes alternatives that are relevant for its interpretation, and the focused item is the candidate that is selected from these alternatives to fill the variable in the question (e.g. Rooth 1992; Dik 1997: 328; Roberts 1998 [1996]; Krifka 2006: 18). Two subtypes of focus were distinguished based on scope: narrow focus or argument focus (the focused constituent is a noun phrase), and broad focus (the focused part of a clause can be identified with the entire comment on an explicit or implicit topic, or entire assertion). Due to the lack of clear-cut correlates, information focus and contrastive focus were not distinguished for the purposes of this study.

Focused items in Jaminjung are characterized by a pronounced falling contour (marked by $\wedge$ in the examples), the onset of which is aligned with the first prosodic word in the scope of focus belonging to a lexical category (Simard 2010: 221, 296). Prosodic phrasing fover and above the correlates of noun phrases-see Simard (-2010: 146-165) was not specifically investigated, but at least impressionistically, there is no difference in prosodic phrasing between focused elements involving or not involving case marking of agents.

The text fragment in (25) illustrates three instances of broad focus, of which the first includes an (ergative-marked) Agent phrase.

(25) $[\wedge$ dibard=biya gani-b-arrga jump $=$ SEQ $\quad 3$ SG $>3$ SG-POT-approach mugmug=ni $]_{\mathrm{FOC}}$

owl=ERG 


\begin{tabular}{|c|c|c|c|}
\hline $\begin{array}{l}{[\wedge \text { wirrij }} \\
\text { angry }\end{array}$ & $\begin{array}{l}g a-y u=n u]_{F O C} \\
{ }_{3} S G-b e . P R S=3 S G . O B L\end{array}$ & $\begin{array}{l}{[b a-\wedge n g a w u} \\
\text { IMP-see }\end{array}$ & $\begin{array}{l}\text { mung! }]_{\mathrm{FOC}} \\
\text { look.at }\end{array}$ \\
\hline
\end{tabular}

(IP; ESgT_AO3_O1.230)

The staged dialogue in (26) illustrates agent phrases-again, all ergative-marked-in narrow (argument) focus; it also shows that constituents in argument focus are variable in their position. Constituent order appears to be related to accessibility of a discourse referent rather than to the information structure category or a feature like exhaustiveness or contrastiveness.

$$
\begin{aligned}
& \text { "[nanggarni }]_{F O C} \quad \text { gan-uga }=r r g u \\
& \text { who:ERG } \\
& { }_{3} \mathrm{SG}>3 \mathrm{SG} \text {-take.PST }=1 \mathrm{SG} \text {.OBL } \\
& \text { ngarrgina } \\
& \text { 1SG:POSS } \\
& \text { "aa majani }[\text { jarlig }=\wedge \text { burlu }=n i]_{F O C} . \text { burr-uga" } \\
& \text { ah maybe child }=\mathrm{COLL}=\mathrm{ERG} \quad{ }_{3} \mathrm{PL}>3 \mathrm{SG} \text {-take.PST }
\end{aligned}
$$

\section{dijan}$$
\text { dubuluj?" }
$$

' "ah, maybe the children took it"'

$$
\begin{aligned}
& \text { (...) "yawayi, yawayi, burr-uga [jarlig=burlu=ni" }]_{F O C} \\
& \text { yes yes }{ }_{3} \mathrm{PL}>3 \mathrm{SG} \text {-take.PST child=COLL=ERG } \\
& \text { (...) "'yes, yes, the children took it"' } \\
& \text { (JM, ESo8_A2O_03.080-86) }
\end{aligned}
$$

Agent phrases occurring as afterthoughts, i.e. separated from the remainder of the clause by a strong prosodic break, were subsumed under the category of narrow focus (for an example see (7)). Afterthoughts serve to assert additional information which semantically belongs to the preceding unit. Afterthoughts in Jaminjung are distinguished from right-dislocated topics (see below) by the presence of a pitch reset and a focal contour (Simard 2014); this distinction is recurrent cross-linguistically (Aijmer 1989; Ziv 1994; Averintseva-Klisch 2008).

The analysis of topics is based on a generally accepted definition of a (sentence) topic as an overt constituent denoting "what the sentence is about"; the topic specifies an address (or "filing card") in the common ground between speaker and addressee to which the information in the remainder of the utterance is to be added (Reinhart 1981; Lambrecht 1994; Jacobs 2001; Krifka 2006; Maslova and Bernini 2006). For the purposes of this overview, no further distinctions e.g. between contrastive and shifted topics are applied.

As is cross-linguistically common, topical constituents occur in clause-initial position in Jaminjung. They are identifiable as topics because they precede the constituent associated with a focal pitch contour at its left edge, as illustrated for an agent noun 
phrase in (27) and (22), and for an object noun phrase in (28). The prosodic contour of the topic constituent itself can be variable; while it often ends in a rise (indicating continuation), this is not necessarily the case.

(27) $[\text { yirri=biya }]_{\mathrm{TOP}-\mathrm{L}}\left[{ }^{\wedge} \text { munuwi yirr-arra-m }\right]_{\mathrm{FOC}}$ ${ }_{1} \mathrm{PL} . \mathrm{EXCL}=\mathrm{SEQ}$ native.bee ${ }_{1} \mathrm{PL}$.EXCL $>{ }_{3} \mathrm{SG}$-put-PRS 'as for us, we call them munuwi' (as opposed to speakers of other languages who have other terms for the native bee)

(IP, ES97_A03_01.188)

(28) $[\text { gunurr }]_{\mathrm{TOP}-\mathrm{L}} \wedge$ [jarlig=ni gan-antha $]_{\mathrm{FOC}}$ bag child=ERG ${ }_{3} S G>3$ SG-take.PRS

'the bag, a child is carrying it'

(IP, ESo8_A2O_01.093)

Topical constituents can also be positioned at the right edge of a clause in Jaminjung; these signal reactivation of a topic rather than shift to a new topic (Simard 2014), again in line with cross-linguistic observations (Givón 1983a; Ziv 1994; Lambrecht 2001). Right-edge topics are distinguished from afterthoughts (see above) by a flat, non-focal contour. In the Frog Story retelling from which (29) is taken, the dog has been a protagonist from the beginning of the narrative, and has been frequently mentioned. This example also shows that a right-edge topic (here, the agent) can co-occur with a left-edge topic (here, the object).

(29) $[\text { janju=malang mulanggirrng }]_{\mathrm{TOP}-\mathrm{L}}[j a g \quad \underline{\text { na }} \text { gan-angu, }]_{\mathrm{FOC}}$ $\mathrm{DEM}=\mathrm{GIVEN}$ dangerous go.down now ${ }_{3} \mathrm{SG}>3 \mathrm{SG}$-get/handle.PST

$[\text { wirib }=\text { ni=malang }]_{\mathrm{TOP}-\mathrm{R}}$

$\operatorname{dog}=\mathrm{ERG}=\mathrm{GIVEN}$

'those dangerous ones (i.e. bees), he got them down, the dog' (CP, ES96_A18_02.069)

Importantly, information structure as defined here is distinct from referential status in discourse, as captured by categories such as givenness, accessibility to the hearer, specificity, or definiteness. There are of course well-known correlations e.g. between topicality and high accessibility, and discourse-new referents and focal status, but these are not absolute. Referential status was not investigated, partly because Jaminjung lacks clear formal correlates such as definite articles. The exclusion of definiteness also seems justified by the result of a recent study reporting no influence of definiteness on differential agent marking (as opposed to differential object marking) cross-linguistically (Fauconnier and Verstraete 2014).

The investigation of the interaction of information structure categories and agent marking in Jaminjung reveals clear trends but-again-no clear-cut association, in other words, ergative marking is variable with all information structure categories. Excluding from consideration clauses with quotations as objects, which favour zero-marking (section 44.4.2), and moreover in most cases feature agent phrases in the background rather than as topic or focus, agents are almost exclusively case-marked under both broad and narrow focus (in well over 90\% of cases in the preliminary study). Most of 
the exceptions are speech act participant pronouns-in other words, the strong tendency for focal agents to be marked can be overridden by the factor person (see section 44.5 for further discussion). Prosodically integrated agent NPs in argument focus and afterthoughts do not differ in their likelihood of attracting case marking.

Agent phrases as topics are much less likely to be case-marked, though marking is still the default (approximately two thirds of all topical agents receive case marking). The preliminary study suggests some effect of prosodic detachment, with prosodically (leftor right-) detached topics more likely to be zero-marked. In addition, the semantic factors discussed in section 44.4.2 play a major role in determining the presence or absence of case marking on topical agents (for details see Schultze-Berndt and Meakins in prep.); for example, in the preliminary study, no first or second person pronoun in topic position receives ergative marking.

In sum, in addition to the semantic factors of verb class, tense/aspect, person, and animacy, a basic hierarchy of information structure categories (Focus $>$ Topic) allows one to predict the likelihood of overt agent marking. Focal agents are almost invariably marked; this constraint is overridden mainly by pronominal agents. As a default, topical agents are still case-marked, but in addition to prosodic detachment, the semantic factors favouring zero-marking are more likely to exert their force. Potential explanations for these findings will be discussed in more detail in section 44.5. In the following section, we will briefly investigate the factors underlying ablative- rather than ergativemarking of agents in Jaminjung.

\subsubsection{Focal Ablative Marking of Agents}

In this section, we will return to the issue of a further differentiation within the "casemarked agent" category, achieved by the use of two contrasting case markers. The low overall proportion (below 7\%) of Ablative as agent marker strongly suggests that it is constrained in its distribution compared with the Ergative.

The first such constraint is a restriction of Ablative agent marking to animate entities, ${ }^{3}$ while, as shown in section 44.2.3, ergative-marking is regularly found on inanimate agents. The second striking finding is that the majority (68\% in the preliminary study) of Ablative-marked agents in the dataset fall into the category of argument focus, whereas only $44 \%$ of all ergative-marked agents were instances of argument focus (although due to the higher total frequency of ergative marking, the majority of agents in argument focus are still ergative-marked). An example is (30).

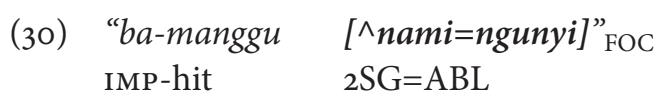

3 In its spatial function, naturally, the Ablative case occurs frequently on inanimates. 


$\begin{aligned} & \wedge \text { burru- } y u=n g u n g g u \\ & \text { }\end{aligned}$ jarlig=ni=gun, ngih?
3PL $>3$ SG-say/do.PST $=2$ SG.OBL $\quad$ child=ERG=CONTR TAG
of echidna hunting, the children being squeamish about handling the spiky
creature)
(EH, ESo8_Ao4_06.467)

This difference in distribution suggests that Ablative marking is favoured by contexts where the identity of the agent is noteworthy or under discussion. This in fact also holds for the few cases where the Ablative-marked agent falls under a different information structure category. All three examples of topical Ablative-marked agents in the preliminary study involve an explicit contrast between two topics, as in (31).

\section{(31) [waitbala $=$ ngunyi $]_{T O P}$ Blue Bone burr-arra-m white.person $=\mathrm{ABL} \quad$ Blue Bone $3 \mathrm{PL}>3 \mathrm{SG}$-put-PRS}

'(what do we call that fish species?), the white people call it Blue Bone'

(EH, ESo8_Ao4_06.087)

Given the low number of Ablative-marked agents in the preliminary dataset (and corpus data more generally), and the lack of any historical documentation of the rise of this construction, these observations do not allow for firm generalizations. The striking correlation between Ablative-marking and argument focus, however, suggests that this infrequent construction is mainly used to indicate unexpected or contrastive agents, in a way that is very similar to the focal ergative marker in Warrwa (McGregor 2006; McGregor and Verstraete 2010: 1614-1615). Moreover, while Ablative and Ergative both serve as agent markers, they do not correspond to the same semantic role. The Ergative encodes the semantic role of effector, encompassing any participant which serves to bring about an effect, including natural forces, other inanimates, and instrument (section 44.2.3), while the Ablative requires that the agent is animate and volitional.

\subsection{DisCUSSION AND IMPLICATIONS}

The investigation of "optional" ergativity in Jaminjung presented here reveals yet another instance of "soft constraints mirroring hard constraints" (Bresnan et al. 2001)—or possibly the reverse. In other words, the same factors that are also potentially relevant for consistently split ergative systems play a role in fluid or variable systems of agent marking (see also McGregor 2010: 1616): lower animacy of the agent, past perfective tense/aspect, and a higher degree of effectiveness/impingement of the event on an undergoer. In addition, the findings show a strong tendency for focal agents to be marked, which intriguingly manifests itself in the existence of an infrequent second, "focal" ergative marker (taking the form of the Ablative case) which mainly occurs in the condition of argument (narrow) focus. 
These findings reflect a competition between two overarching constraints which has been invoked in recent applications of optimality theory to differential case marking: semantic Faithfulness, favouring overt marking of the agent role (corresponding e.g. to Aissen's $1999 b{ }^{\star} \theta$, Zeevat and Jäger's 2002 "Generation”, Malchukov's 2008a "indexing", and de Hoop and Malchukov's 2007 "Identify"), and Economy, favouring the absence of any marking (corresponding e.g. to Aissen's 1999b *STRUC and Zeevat and Jäger's 2002 and Malchukov's 2008a "Economy"). In some of these works, the interaction of the two constraints has been modelled by a notion of "argument strength" which directly correlates with the marking pattern, but in turn is determined by a - not clearly specified-language-specific interaction of factors (De Hoop 1999: 103; De Hoop and Narasimhan 2009: 72-76). The problem with this notion of argument strength is that it allows for the mapping but does not in itself provide an explanation for the cross-linguistic patterns found in the data, or encompass predictions of the nature and direction of the factors underlying it. More interesting generalizations can be arrived at by examining the actual factors which seem to recurrently influence differential case marking-in this case case-marking on agents. Some of the factors also applying to Fluid Ergative marking in Jaminjung, but also to split and Fluid systems elsewhere, relate to the completedness of the action and affectedness of an object-both favouring the presence of ergative marking (section 44.4.2). Others correspond to the factors of person and animacy, originally proposed by Silverstein (1986) and supported by neurolinguistic evidence (see Bornkessel-Schlesewsky and Schlesewsky 2015 for a review). The discourse expectation (cf. Zeevat and Jäger's (2002) "bias") for speech act participants to be agents makes ergative-marking redundant, i.e. Economy will prevail; conversely, the expectation for inanimates to be non-agents will result in near-categorical marking of inanimates in the agent role (section 44.4.2).

The role of information structure is similarly motivated. An expectation for agents to be topics will result in a near-categorical agent-marking in focus position (section 44.4.3): given the definition of focus assumed here, the role of a given entity as an agent is, by definition, under discussion when the corresponding constituent is in the scope of focus. This favours the actual marking of the agent role, a constraint which can however be overridden by semantic factors, in particular person. It does not follow, however, that the identity of the agent can be predicted when the corresponding constituent is in topic position. Since in languages like Jaminjung, the tendency is for any argument to be elided if discourse-given, the default for an agent in the role of discourse topic will be omission. If an agent phrase functions as an overt sentence topic, it is therefore usually because it contrasts with another potential agent, is a shifted topic, or has not been mentioned in the immediately preceding discourse. In this view, the relatively high rate of ergative marking on topics is still consistent with the overarching motivation of unexpectedness favouring overt marking of the agent role.

Under the account just presented, ergative (or ablative) marking does not serve to mark focus, any more than it serves to mark a low rank in the animacy hierarchy. These conditions are merely those where the entity in the agent role is less expected to fill this role, and hence more likely to be marked (because of the intrinsic association of focus 
with an open variable in the first case, and the heuristics of associating agents with higher animates and in particular with speech act participants in the second case). Rather, synchronically, Ergative marking is closely tied to the (language-specific) semantic role of effector (see section 44.2.3). This language-specific semantics comes into play over and above the general tendencies discussed above governing the likelihood of agent marking in general, and thus constrains their applicability. Thus, while in some languages only animate, controlling, or volitional agents may receive ergative marking (or indeed appear in first argument position), in Jaminjung the Ergative marker is compatible with all participants which have the semantic role of "effector", i.e. which play a causal role in bringing about an event impinging on an undergoer (which includes instruments); volitionality or control is entirely irrelevant. A distinct semantic representation is required for the second agent marker (formally identical to the Ablative), since it is only found with animate, controlling agents which are the ultimate cause of an event. The factors of verb semantics, tense/aspect, animacy, and information structure merely make the marking of the role more relevant, or conversely make omission of the markers, under considerations of economy, more permissible.

There is however some intriguing evidence that the diachronic origin of the Ergative marker $=n i$ is more directly related to marking expectedness in discourse than it is to marking the semantic role of agent. The origin of the Ergative marker in Jaminjung/ Ngaliwurru is, in all likelihood, a third person pronoun/demonstrative; compelling comparative evidence for this claim is gender agreement of ergative case in the related languages Nungali and Jingulu (Chadwick 1976b; Pensalfini 1999; McGregor 2008). Synchronically, in Jaminjung/Ngaliwurru, the pronominal $n i$ is retained in ${ }_{3} \mathrm{SG}>{ }_{3} \mathrm{SG}$ verbal prefix $g a n i$ - and is a plausible origin for the verbal enclitic $=n i$ marking switchreference across finite clauses (see section 44.3 for discussion and examples). Plausibly, a discourse use of a third singular pronouns to disambiguate reference in the case of a switched or new subject/agent could be the origin (via distinct pathways of grammaticalization) for both the switch-reference construction and the Ergative marker (the latter by an association of switched or new subjects in apposition with the pronoun with the role of transitive agent, a scenario discussed in more detail by McGregor (2008: 311316)). For a number of other Australian languages, too, there that markers of a special discourse status have been reanalysed as ergative markers, or vice versa (Jingulu, Pensalfini 1999; Kuuk Thaayorre, Gaby 2010).

In sum, the findings for Jaminjung/Ngaliwurru can be accounted for well by the assumption of a language-specific semantics of the Ergative marker (or more specifically, the two agent markers in this language), in conjunction with universal but "soft" constraints on the presence vs. absence of marking, which include information structure. They raise issues, on the other hand, for a strict separation of lexical and structural case, since the lexical semantics of the predicate can license Ergative case, but not determine its presence. The factors that do favour or disfavour its presence, moreover, are not related to structure in the strict syntactic sense. Even if information structure was incorporated into the structural assignment of case, the factors of position on the animacy hierarchy and tense/aspect still need to be accounted for. 
Finally, our findings give rise to a cautionary note about the data underlying claims about argument marking systems-specifically the way in which elicited data may miss discourse organizational factors responsible for case marking. This is a point also poignantly made by DeLancey (2011: 13) as well as by Simpson (2012), who points to information structure as a possible (but, given the current state of documentation, difficult to verify) factor in the diachronic development of the "unusual" Arrernte system which has ergative marking on 1st person pronouns, but not on other pronouns.

It is an intriguing thought that the "discovery" of variable argument marking and the factors-including discourse-pragmatic factors-underlying it correlates with the availability of corpora of sound-linked, unedited speech from various genres, and the affinity of authors with corpus-based analyses, as opposed to grammatical descriptions based on elicited utterances and heavily edited texts. In the case of Jaminjung, had the available data not contained instances of personal pronouns in argument focus, Jaminjung might well have given the impression of a language with a strict ergative split between pronouns and other types of nouns, since it turns out that pronouns in an Agent role are never marked outside the argument focus context (this is true not just for the restricted dataset in the preliminary study discussed here, but for every single one of the handful of cases of ergative-marked pronouns found in a relatively large corpus). More generally, the study demonstrates the importance of the availability of both prosodic information and discourse context, as ensured by sound-linked corpora. 